\title{
Liquidity and Manipulation of Executive Compensation Schemes
}

\author{
Ulf Axelson \\ Stockholm School of Economics and SIFR
}

Sandeep Baliga

Kellogg School of Management, Northwestern University

\begin{abstract}
Compensation contracts have been criticized for encouraging managers to manipulate information. This includes bonus schemes that encourage earnings smoothing, and option packages that allow managers to cash out early when the firm is overvalued. We show that the intransparency induced by these contract features is critical for giving long-term incentives. Lack of transparency makes it harder for the owner to engage in ex post optimal but ex ante inefficient liquidity provision to the manager. For the same reason, it is often optimal to "pay for luck" (i.e., tie long-term compensation to variables that the manager has no influence over, but may have private information about, such as future profitability of the whole industry). (JEL G34, J33)
\end{abstract}

How can effective executive compensation be set up when managers can manipulate short-term information? Although it is a long-standing question in corporate governance, public focus on this issue reached new heights at the beginning of the millennium after governance scandals at Enron and WorldCom and many other corporations. A common thread in these scandals was that accounting manipulation was used to increase stock prices. In a number of cases, allegations were made that managers profited from these short-term increases, as their stock compensation packages had relatively short-term maturity and were easy to unwind before the manipulation became apparent. ${ }^{1}$

\footnotetext{
We want to thank Mallesh Pai for research assistance, and Renee Adams, Korok Ray (the AFA discussant), Per Strömberg, Michael Weisbach (the editor), David Yermack, and an anonymous referee for helpful comments. We also want to thank seminar participants at Amsterdam University, SIFR/SITE, Toulouse IDEI, UBC, the AFA meetings in Chicago, the Chicago-Minnesota accounting theory conference, and the CEPR Gerzensee summer meetings. Sandeep Baliga gratefully acknowledges financial support from the Zell Center for Risk Research. Send correspondence to Ulf Axelson, SIFR, Drottninggatan 89, 11360 Stockholm, Sweden; telephone: +468 7285126; fax: +468728 5130. E-mail: ulf.axelson@sifr.org.

${ }^{1}$ For example, Enron used at least two questionable ways to inflate earnings. First, they booked the net present value of future income from contracts as earnings in a given year, giving them substantial freedom in assumptions about future cash flows and discount rates. Second, they set up affiliates called "Special Purpose Entities" to remove debt from their balance sheet (see, for example, Healy and Palepu 2003). Officers at Enron engaged in heavy selling before revealing a third-quarter loss of $\$ 638$ million on October 17, 2001. Amalgamated Bank contended in a lawsuit that Enron officers and directors made misleading statements about the company and sold about $\$ 1$ billion worth of stock in the three years leading up to the time the scandals broke. (New York Times, December 16, 2001). Further, in the year before the bankruptcy, top executives withdrew a combined $\$ 32$ million from their deferred compensation accounts, even though there was a $10 \%$ penalty for doing so (Wall Street Journal, November 10, 2002). (We thank David Yermack for pointing this article out to us.)
}

(C) The Author 2008. Published by Oxford University Press on behalf of The Society for Financial Studies. All rights reserved. For Permissions, please e-mail: journals.permissions@oxfordjournals.org. doi:10.1093/rfs/hhn095

Advance Access publication November 26, 2008 
There is also more systematic evidence that managers utilize and hide information to increase their compensation at the expense of shareholders. Bartov and Mohanram (2004) examine 1200 public companies from 1992 to 2001 and show that large stock option exercises by top executives are followed by abnormally low stock returns. Further, in the period preceding exercise, discretionary earnings are abnormally high, and fall to abnormally low levels after exercise, suggesting that managers opportunistically pump up the stock price by managing earnings prior to exercise.

In the wake of the scandals, a number of economists have drawn at least two conclusions about how corporate governance must be improved: Companies should make it harder for executives to unwind stocks and options, and transparency should be increased to make manipulation more difficult. ${ }^{2}$ The Sarbanes-Oxley Act of 2002 contains provisions not only to thwart manipulation by increasing transparency, but also to make insider trading and early cashing out harder. ${ }^{3}$

These commonsensical prescriptions are in accordance with standard agency theory. The "informativeness principle" (coined by Holmström 1979) states that managers' pay should be tied to a measure that is as informative as possible about managerial effort. Then, if long-term measures of performance are harder to manipulate and are more informative, the manager's pay should be long term. Also, it should be beneficial to make signals as informative as possible by making manipulation harder, or by increasing transparency in other ways. This is also the natural conclusion that can be drawn from the signal-jamming model of Stein (1989), which shows that managers will spend costly effort to distort short-term signals when they are compensated on the short-term stock price, even when the market is not fooled by the distortions.

In this paper, we argue that this reasoning is incomplete and sometimes wrong when ex post Pareto-improving renegotiation cannot be ruled out. We show that there is an inherent conflict between increasing transparency and

2 See, for example, Holmström and Kaplan (2003); Bebchuk and Fried (2004); Jensen and Murphy (2004); and Bolton, Scheinkman, and Xiong (2006). Bolton, Scheinkman, and Xiong (2006) show that managers have an incentive to increase earnings to inflate short-term stock prices, and that in fact an optimal contract may encourage this, when irrational overconfident investors get fooled. They conclude that longer vesting periods may be socially desirable, but not necessarily for current shareholders. Bebchuk and Fried (2004) state that the early vesting of options is one of the problems of corporate governance. They argue that CEOs should be limited from selling stocks once the option has been exercised: “... firms have given executives broad freedom to unload options and shares, a practice that has been beneficial to executives but costly to shareholders."

${ }^{3}$ Examples of restrictions that make unwinding harder include Section 305, which states that officers must reimburse the firm for any bonuses or gains on stock or option sales gained during a year for which accounting was later found to be noncompliant; and Section 403, which requires directors and officers to disclose trading in company stock within two days. Examples of measures designed to increase transparency include increased requirements on financial accounting, independence of auditors, and requirements on financial sophistication of directors. 
increasing the maturity of compensation. Indeed, increasing transparency by, for example, making manipulation harder can make the firm strictly worse off because of the negative effects on long-term incentives.

Our basic argument is that when managers have some preference for early consumption, it is hard to commit to long-term contracts even when they are ex ante optimal. After a manager has put down the effort induced by a longterm contract, the contract no longer serves any incentive purpose. Because the manager is impatient, it is therefore in the interest of both the investors and the manager to accelerate payments. We show that if short-term signals are observed by both the manager and the investors (the case of no manipulation), there is nothing preventing such renegotiation, so contracts must be short term.

Now suppose the manager can manipulate the short-term signal, making it even less informative to the investors. This has the disadvantage of making it even harder to incentivize the manager with short-term contracts. The advantage is that it may now be possible to commit to long-term contracts because manipulation introduces a lemons problem at the renegotiation stage that reduces the scope for trade. To induce optimistic managers to take an early payment, the payment must be large. But this means that pessimistic managers will gain at the expense of the investors, so they may be better off not renegotiating. If the short-term signal is not very informative and the manager is not too impatient, a long-term contract with manipulation will dominate a short-term contract with full transparency.

The optimal contracts we derive are consistent with several observed features of compensation packages that are remarkably persistent over time and across firms, but that are hard to explain with existing theories.

For example, although most executive stock options tend to have expiration times of about 10 years from the grant date, they often have vesting schedules that allow managers to start exercising options as soon as one year after the grant date. ${ }^{4}$ This seems puzzling from the perspective of the informativeness principle. Not only does it make the contract relatively short term, but the maturity of compensation is decided by the manager himself, after he has observed his own private information about how the firm is doing. This gives managers an incentive to increase short-term earnings and cash out early when they know the stock is overvalued, thereby reducing the link between pay and performance.

We show that such vesting clauses are always part of an optimal longterm contract. The reason is that, although asymmetric information at the renegotiation stage can make it credible for the principal not to pay all managers early, it is impossible to prevent him from giving an offer of a low early payment

\footnotetext{
4 A typical plan would allow one quarter of the options to be exercised after one year, and an extra quarter in each of the following three years (see Kole 1997). Kole, examining the 1980 S\&P 500 firms, calculates that the average time before any options are allowed to be exercised is 13.5 months, and that the average option can be exercised after 23.6 months.
} 
that only the most pessimistic managers will accept. From this perspective, early vesting by managers who have inflated the stock price is an unfortunate but unavoidable consequence of lack of commitment, but the alternative where manipulation is ruled out would be no long-term incentives at all.

Our analysis also provides a new explanation for why firms usually do not use relative performance evaluation, but rather pay managers for absolute stock price increases, part of which may be due to observable factors outside the control of the manager, such as generally favorable industry conditions. This "pay for luck" may be optimal if the manager can see an early signal about industry conditions before they become available to the market. If a longterm contract with relative performance evaluation is used, there may not be enough adverse selection about the value of the long-term pay at the time of renegotiation. However, if the contract is also contingent on a variable that the manager has private information about in the short term, a long-term contract that provides effort incentives can be made renegotiation proof. ${ }^{5}$

Finally, our model gives a rationale for features of standard bonus packages that are contingent on some accounting measure such as earnings. Bonuses still constitute a large fraction of compensation in most companies, and arguably create even larger incentives to destroy information than executive stock options. As documented by Murphy (1999), the size of the yearly bonus is typically zero below a lower target threshold of the performance measure and caps out at a higher threshold. ${ }^{6}$ This gives incentives to exaggerate earnings if the lower threshold is not expected to be met, and decrease earnings (e.g., by shifting the reporting of sales to next year) if the earnings are expected to be above the higher threshold to make it easier to meet next year's bonus. ${ }^{7}$ Thus, earnings will appear to be relatively smooth and contain little information on which to base rewards for the manager.

We show that these thresholds can be used in an optimal contract to induce the "right" amount of transparency. Our argument builds on the assumption that it is easier to hide good information (e.g., by pushing sales into the next period) than to fabricate good information when there is none. By setting a cap on the bonus at a certain threshold of the performance measure, managers are encouraged to smooth earnings. The lower the threshold is, or the less highpowered the short-term pay-for-performance is, the easier it is to hit the target earnings, and the less transparent the firm will be. The optimal contract will set

\footnotetext{
5 Oyer (2004) proposes a model in which pay for luck is explained by the fact that managers' outside opportunities are positively correlated with the profits or stock price performance of the firm. Lazear (2004) proposes a "sorting" explanation in which managers have private information about the prospects of the firm and accept compensation contingent on the prospects to signal to outsiders that the firm is worth investing in.

${ }^{6}$ Long-term incentive plans based on accounting measures over several years have the same structure (see Murphy 1999).

7 See Healy (1985); Holthausen, Larcker, and Sloan (1995); and Gaver, Gaver, and Austin (1995) for empirical evidence that bonus packages induce this type of manipulation.
} 
the bonus region to trade off the commitment advantage of lower transparency with the better incentive effects of higher pay-for-performance.

Our analysis casts some doubts on the merits of legislation geared at forcefully increasing transparency or in other ways restricting contracting opportunities in firms. If firms can influence transparency by structuring contracts in the right way, ruling out manipulation might have the unintended consequence of eliminating beneficial long-term contracts. Although it is hard to claim that Enron and WorldCom had good corporate governance, it may be even more of a stretch to argue that all companies are run by self-serving or incompetent boards of directors. Yet virtually all firms use the type of contracts described above, even when they create more manipulation and less transparency than contracts that standard agency theory would prescribe.

Our work builds on the literature on renegotiation-proof contracts developed in Hart and Tirole (1988); Dewatripont (1989); and Fudenberg and Tirole (1990). Dewatripont shows in the context of a labor model that in a renegotiation-proof optimal contract, information is resolved slowly through time relative to a full-commitment level. Fudenberg and Tirole have a moralhazard model closer to ours with a risk-neutral principal and a risk-averse manager. Although they do not study optimal contracts under manipulation and do not explicitly focus on transparency, they show that asymmetric information is essential to providing incentives in a renegotiation-proof contract. The asymmetric information in their model arises through managers choosing a mixed strategy in their effort provision, and the optimal contract has option-like characteristics just as ours. ${ }^{8}$ Cremer (1995) shows in a symmetric information environment that less but common information at an ex post stage may help a principal commit not to renegotiate. We show that asymmetric information can curtail renegotiation, and hence create a commitment mechanism.

Our paper is also related to the literature on soft budget constraints, where a similar conflict between ex post and ex ante efficiency appears. Dewatripont and Maskin (1995) show that a lender without deep pockets can commit not to bail out failing firms and hence create better ex ante incentives for effort. In our setting, where the lender does have deep pockets, asymmetric information is the vehicle for preventing renegotiation.

Myers and Rajan (1998) suggest that if assets are too liquid, it is easy for a manager to steal them. However, they do not study the impact of liquidity on ex ante incentives. They also take an incomplete contracts approach where liquidity is exogenously specified, whereas we use a mechanism design approach.

The structure of the paper is as follows. In Section 1, we lay out the model. In Section 2, as a benchmark, we study the case where the firm can commit

\footnotetext{
8 The solution with a mixed strategy equilibrium is less efficient than the one we have studied. This is because mixing leads to suboptimally low effort provision. In contrast, with manipulation, we show the first best effort can be supported since the asymmetric information is created through (costless) manipulation.
} 


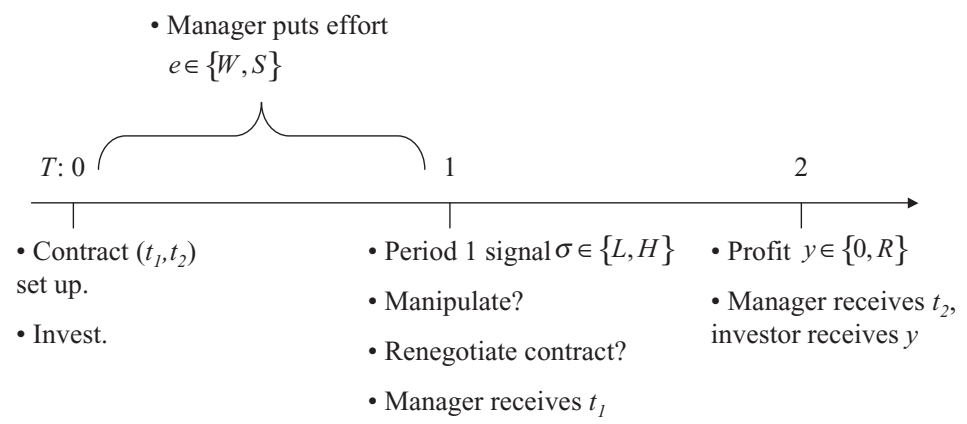

Figure 1

Timeline for the model

ex ante to a contract, and verify the conclusions from the informativeness principle. In Section 3, we study renegotiation-proof contracts and show that zero transparency can dominate full transparency, and that long-term compensation should be in the form of options that are possible to exercise early. Section 4 shows the benefit of pay-for-luck compensation schemes, while Section 5 shows how the optimal amount of transparency can be induced by giving the manager the right incentive to smooth earnings. Section 6 discusses empirical implications, while Section 7 concludes.

\section{Model}

A firm has a project that costs a dollar to finance. The manager does not have funds to finance the project and must look to outsiders for the necessary capital.

The timing of the model is shown in Figure 1. There are three periods, 0,1 , and 2. A contract between an investor and the manager is set up at period 0 . Between periods 0 and 1, the manager exerts unobservable effort $e \in\{W, S\}$. Profit is realized in period 2. Working $(e=W)$ leads to profit $y=R$ with probability $p$ and profit $y=0$ with probability $1-p$; shirking leads to profit 0 with certainty. Working has a private $\operatorname{cost} d$ to the manager. Therefore, the expected gross profit of the project is

$$
\begin{array}{rll}
p R & \text { if } & e=W \\
0 & \text { if } & e=S .
\end{array}
$$

The investor is risk neutral and indifferent between consumption, and hence transfers at periods 1 and 2:

$$
u_{I}\left(c_{1}, c_{2}\right)=c_{1}+c_{2}
$$


where $c_{T}$ is consumption at period $T \in\{1,2\}$. The manager, on the other hand, always prefers to be paid at period 1 rather than period 2:

$$
u_{M}\left(c_{1}, c_{2}\right)=c_{1}+\lambda c_{2} \text { where } 0 \leq \lambda<1 \text {. }
$$

For a similar assumption on managerial impatience, see, for example, Aghion, Bolton, and Tirole (2004) or Holmström and Tirole (1997). The discount parameter $\lambda$ can be interpreted as the cost of having managerial wealth tied up in long-term compensation, rather than being able to smooth income perfectly intertemporally. Alternatively, it can represent an opportunity cost of capital for the manager (e.g., if he has new project ideas in period 1 that need financing). ${ }^{9}$ We assume that $p R-1-d>0$, so that the first best is to finance the project, implement high effort, and pay the manager in period 1 . Since effort is not observable, the first best will typically not be achievable. In exchange for financing the project, the investor gets the profit and transfers $t_{1}$ and $t_{2}$ to the manager in periods 1 and 2 . The manager has limited liability, so the transfers have to be nonnegative. The transfers can be contingent only on observable information; hence, the period 1 transfer cannot be contingent on profits. We assume that in period 1, all that is observed is a profit forecast $\sigma \in\{L, H\}$ which we call earnings. Conditional on profits, earnings are distributed as follows:

$$
\begin{aligned}
& P(H \mid y=R)=\theta>\frac{1}{2} \\
& P(H \mid y=0)=1-\theta<\frac{1}{2} .
\end{aligned}
$$

A high signal $H$ is more likely if future profits are high. Since profits are informative about effort, and period 1 signals are informative about profits, the signal in period 1 is also informative about effort but less so than profits. ${ }^{10}$ This is what creates a role for long-term contracts. Although it is costly to pay an impatient manager late, tying the manager's pay to the long-term signal makes the pay-for-performance relationship stronger. ${ }^{11}$

Our notion of transparency is the degree to which the period 1 signal is manipulable by the manager. Full transparency is when earnings cannot be

${ }^{9}$ We conjecture that our results would be qualitatively unchanged if we instead assumed that investors and managers discount at the same rate but managers are risk averse, as in Fudenberg and Tirole (1990). In that case, it is ex post efficient to renegotiate a risky long-term payment to a risk-free short-term payment. However, the analysis with risk aversion is much less tractable and makes for a more cluttered exposition.

10 To see that $\sigma$ is a weaker signal about effort than profits, note that

$$
\begin{aligned}
& \frac{P(R \mid S)}{P(R \mid W)}=0<\frac{P(H \mid S)}{P(H \mid W)}=\frac{1}{\frac{\theta}{1-\theta} p+1-p}< \\
& \frac{P(L \mid S)}{P(L \mid W)}=\frac{1}{\frac{1-\theta}{\theta} p+1-p}<\frac{P(0 \mid S)}{P(0 \mid W)}=\frac{1}{1-p} .
\end{aligned}
$$

11 In fact, because high profits can only occur if the manager works, a contract that pays the manager only if profits are high would achieve the first best if the manager were not impatient. 
manipulated so that both the manager and the investor observe $\sigma$ in period 1. Zero transparency is when the manager can freely manipulate the period 1 signal, so that the investor sees nothing in period 1 . We will start by analyzing these two extreme forms of transparency. In Section 5, we will study the intermediate case where manipulation succeeds with some probability, which allows us to analyze the optimal amount of transparency and how it can be induced endogenously with an appropriate compensation package.

We start by describing the benchmark case in which there is full commitment. For this case, full transparency is optimal, and we replicate the standard prescriptions of agency theory that lie behind much of the criticism that economists have launched against real world contracts. We then introduce renegotiation and show that zero transparency can dominate, and that the optimal contracts have many of the criticized features.

\section{The Full-Commitment Benchmark}

Assume first that both investors and managers observe $\sigma$, so that the period 1 signal is fully contractible. A contract is then a payment $t_{1}(\sigma)$ to the manager in period 1 as a function of earnings $\sigma$, and a payment $t_{2}(y, \sigma)$ in period 2 as a function of the period 2 profit and earnings. We solve for contracts that maximize the manager's payoff and give him the incentive to work, subject to the break-even constraint of the investor and the limited liability constraint for the manager. Any contract that gives the manager the incentive to work while satisfying the limited liability and break-even constraints is feasible. If it also maximizes the manager's payoff, it is optimal.

Many properties of the optimal contract follow from the informativeness principle. First, as period 1 earnings are a more garbled signal of effort than period 2 profit, it is optimal to make period 2 payments dependent on period 2 profit alone. Second, as zero output in period 2 and low earnings in period 1 are more likely when the manager shirks, it is optimal to set payments to zero in those cases. ${ }^{12}$

Hence, the optimal contract is the solution to the following program:

$$
\max _{t_{1}(H), t_{2}(R)} P(H \mid W) t_{1}(H)+\lambda P(R \mid W) t_{2}(R)
$$

subject to the moral-hazard constraint

$$
P(H \mid W) t_{1}(H)+\lambda P(R \mid W) t_{2}(R)-d \geq P(H \mid S) t_{1}(H),
$$

the break-even constraint

$$
P(H \mid W) t_{1}(H)+P(R \mid W) t_{2}(R) \leq p R-1,
$$

12 The proofs of these properties are straightforward and are omitted. 
and limited liability

$$
t_{1}(H), t_{2}(R) \geq 0
$$

The left-hand side of the moral-hazard constraint is the expected payoff to the manager from working, while the right-hand side is the expected payoff from shirking. Note that the break-even constraint must always bind at the optimum, since otherwise increasing either $t_{1}(H)$ or $t_{2}(R)$ will increase the maximand while relaxing the moral-hazard constraint.

The manager can be given the incentive to work through a mixture of two types of contracts. At one extreme, in a short-term contract, the manager is paid if and only if period 1 earnings are high: $t_{1}(H)>0$ and $t_{2}(R)=0$. From the moral-hazard constraint, we can calculate the lowest expected $\cos t c_{s}$ to the investor of giving the manager the incentive to work with a short-term contract as

$$
c_{s} \equiv P(H \mid W) t_{1}(H)=\frac{d}{1-\frac{P(H \mid S)}{P(H \mid W)}} .
$$

If such a short-term contract is feasible (i.e., costs less than $p R-1$ ), it is optimal as it maximizes social surplus by paying the manager only in period 1 .

At the other extreme, in a long-term contract, the manager is paid if and only if the final profit is high: $t_{1}(H)=0$ and $t_{2}(R)>0$. The lowest expected cost to the investor of inducing work with a long-term contract can be calculated from the moral-hazard constraint as

$$
P(R \mid W) t_{2}(R)=\frac{d}{\lambda}
$$

Note that the cost of inducing work with either a short- or a long-term contract is higher than the manager's private cost $d$ of working. Inducing the manager to work with a short-term contract is costly because, if the manager shirks, he still gets a positive payoff if the short-term signal is high. Therefore, he has to be paid an efficiency wage to give him the incentive to work. The longterm contract is costly because it pays in period 2, when the manager values consumption less. We are especially interested in the case where long-term pay is cheaper to the investor, so we assume

$$
\lambda \geq 1-\frac{P(H \mid S)}{P(H \mid W)} .
$$

In this case, it is cheaper for the investor to induce high effort with a longterm contract than with a short-term contract. Hence, if a long-term contract is infeasible, so is a short-term contract and it is impossible to give the manager the incentive to work.

Finally, if a long-term contract is feasible but a short-term contract is not, the optimal contract is a mix of long-and short-term compensation. In this 
case, both the moral hazard and the break-even constraint bind at the optimum. The moral-hazard constraint has to bind since if it does not, it is possible to reduce the second-period payment, increase the first-period payment, and increase the manager's payoff without violating the moral-hazard constraint. ${ }^{13}$ The following proposition collects our results and gives the solution to the problem under full commitment.

Proposition 1. With full commitment and full transparency, if a short-term contract is feasible, then at the optimal contract $t_{1}(H)>0$ and all other payments are zero. If a long-term contract is not feasible, then it is impossible to implement full effort. If a long-term contract is feasible but a short-term contract is not, then at the optimal contract $t_{1}(H)>0, t_{2}(R)>0$ and all other payments are zero.

Now suppose that we have zero transparency, so that the manager can freely manipulate the earnings signal. Then, a short-term contract cannot implement high effort as there is no contractible signal with which to give incentives. Only long-term contracts are possible. Therefore, under full commitment, full transparency dominates zero transparency as it increases the set of feasible contracts. Financial regulations that seek to increase transparency are motivated by this feature of the full-commitment benchmark. Also, several other features of the full-commitment solution seem to be the basis for much of the criticism that economists have launched against real world contracts.

\subsection{Fixed maturity}

The optimal contract depends only on earnings $\sigma$ and the final profit $y$. With zero transparency, the optimal contract only depends on $y$. This rules out menus of payments where the manager self-selects into a payment schedule after observing his private information. The vesting schedule used for executive stock options, where the manager has the right to exercise his options early, is an example of such a menu. However, with full commitment, there is never any gain from allowing the manager to choose the maturity of compensation himself.

\subsection{No pay-for-luck}

Suppose that profits are also affected by variables that are completely outside the control of the manager, such as the general state of the industry. Also,

13 Solving for $P(H \mid W) t_{1}(H)$ from the moral-hazard constraint, we have

$$
P(H \mid W) t_{1}(H)=\frac{\lambda(p R-1)-d}{\lambda-1+\frac{P(H \mid S)}{P(H W)}},
$$

and solving for $P(R \mid W) t_{2}(R)$ from the break-even constraint, we have

$$
P(R \mid W) t_{2}(R)=p R-1-P(H \mid W) t_{1}(H) .
$$


suppose that these variables are independently observable. For example, the general state of the industry can be extracted from an index of stock prices of other firms in the industry in period 2 . Then, there would be no reason to make the manager's compensation contingent on these absolute performance variables as they are outside his control. A relative performance contract that compensates the manager only to the extent that the firm outperforms the rest of the industry is optimal.

In the next section, we introduce renegotiation, and show that zero transparency can often dominate full transparency. Further, we show that it is optimal to allow the manager to choose the maturity of his compensation. In Section 4, we show that it is often optimal to make pay contingent on variables outside the control of the manager. In Section 5, we generalize the model to allow manipulation by the manager to succeed with some probability. We show that the optimal amount of transparency can be induced by a bonus contract with an earnings target that is set to incentivize the right amount of earnings smoothing.

\section{Renegotiation-Proof Contracts}

Suppose now that at time $t=1$, after the public signal is observed, the investor can propose a new contract that will be accepted if the manager is at least as well off as under the old contract. ${ }^{14}$ A contract is renegotiation proof if there is no other incentive-compatible contract that reduces the investor's expected payment and is acceptable to the manager.

Note first that no short-term payment can be renegotiated into a long-term payment. This is so since long-term payments lower the ex post social surplus because of the manager's impatience. Therefore, either the manager or the investor will be worse off after such a renegotiation, which means that they will never be able to agree to change the initial contract. Thus, all short-term payments are renegotiation proof. The issue is whether long-term payments can be made renegotiation proof.

We begin by studying the case of full transparency. With full transparency, renegotiation drastically reduces the space of feasible contracts, because only short-term contracts turn out to be renegotiation proof. To see this, suppose that a candidate's long-term contract pays $t_{2}(R)>0$. In period 1 , suppose that $\sigma=H$ has been observed. Then, in place of the long-term contract, the investor can offer to pay the manager an extra $t_{1}^{\prime} \equiv \lambda t_{2}(R) P(R \mid H, W)$ in period 1 ,

\footnotetext{
14 If the manager offers the new contract, there is a signaling problem as he knows his effort and is perhaps the only player to observe the period 1 signal. Therefore, there are more equilibria in the renegotiation game. However, the analysis of Maskin and Tirole (1992) suggests that if equilibria must be "strongly renegotiation proof," it does not matter which player makes the renegotiation offer.
} 
which will be accepted by the manager since he is indifferent between the original long-term contract and an early payment of $t_{1}^{\prime}$. The expected gain for the investor from this renegotiation is $(1-\lambda) t_{1}^{\prime}>0$. This reasoning can be extended to any type of long-term payment. Therefore, with full transparency, only short-term contracts can be used. If short-term contracts cannot induce high effort, then no renegotiation-proof contract is feasible.

The case of zero transparency, where managers can freely manipulate earnings so that investors do not observe $\sigma$ at all, is more interesting. As we will see that menus now turn out to be useful, we have to introduce some new notation. A contract is defined as a menu of payments that the manager can choose from by sending a report $r \in\{L, H\}$ after the renegotiation stage is over. Let $t_{1}(r)$ and $t_{2}(y, r)$ be period 1 and period 2 payments for report $r \in\{L, H\}$ and output $y \in\{0, R\}$. Then, a contract is $t=\left\{t_{1}(r), t_{2}(y, r)\right\}_{y \in\{0, R\}, r \in\{L, H\}}$.

Note that when the short-term signal is fully manipulable, it is impossible to make the manager work with a pure short-term contract, since the short-term signal becomes effectively noncontractible. However, it may now be possible to make long-term contracts renegotiation proof. We first show that any longterm contract must have a vesting clause such that the manager can cash out early, and does so if he is pessimistic. We then show that such a contract can be renegotiation proof if the investor faces sufficient adverse selection in the renegotiation game, in the sense that the probability of dealing with a pessimistic manager is high.

Suppose that the initial contract is not a menu but specifies a single long-term payment $t_{2}(R, L)=t_{2}(R, H) \equiv t_{2}(R)$ if the profit is high, and no short-term payment. But then, the investor is better off by proposing a new contract $t^{\prime}$ with a short-term payment that only the pessimistic manager accepts:

$$
\begin{aligned}
t_{2}^{\prime}(R, H) & =t_{2}(R), \\
t_{1}^{\prime}(H) & =0, \\
t_{2}^{\prime}(R, L) & =0, \\
t_{1}^{\prime}(L) & =\lambda t_{2}(R) P(R \mid L, W) .
\end{aligned}
$$

This is a vesting contract with an option to cash out early. Note that this contract is incentive compatible, since the pessimistic manager is indifferent between the early and late payment, while the optimistic manager values the late payment more: $\lambda t_{2}(R) P(R \mid H, W)>\lambda t_{2}(R) P(R \mid L, W)$. Managers are as well off as under the original contract, while the investor is better off since he saves on the long-term payment to the pessimistic manager, so the original contract is renegotiated. In fact, no contract that specifies a long-term payment to a pessimistic manager is renegotiation proof.

Now, we show that the vesting contract $t^{\prime}$ above can be renegotiation proof. Suppose the investor proposes yet another contract $t^{\prime \prime}$ to reduce $t_{2}^{\prime}(R, H)$ and 
increase $t_{1}^{\prime}(H)$ so that an optimistic manager is indifferent:

$$
\begin{aligned}
t_{2}^{\prime \prime}(R, H) & =0, \\
t_{1}^{\prime \prime}(H) & =\lambda t_{2}^{\prime}(R, H) P(R \mid H, W), \\
t_{2}^{\prime \prime}(R, L) & =0 \\
t_{2}^{\prime \prime}(L) & =t_{1}^{\prime}(L) .
\end{aligned}
$$

But now, the short-term payment $t_{1}^{\prime \prime}(H)$ to optimistic managers is higher than the originally promised short-term payment $t_{1}^{\prime}(L)$ to pessimistic managers, so pessimistic managers will have an incentive to deviate and claim they have a high signal. Therefore, the investor will have to pay the pessimistic managers more than under the vesting contract. If this loss is high enough to eat up the gains from trade with the optimistic manager, the contract is renegotiation proof. This happens if

$$
P(L \mid W)\left(t_{1}^{\prime \prime}(H)-t_{1}^{\prime}(L)\right) \geq P(H \mid W)(1-\lambda) P(R \mid H, W) t_{2}^{\prime}(R, H) .
$$

The left-hand side is the expected loss from renegotiation with a pessimistic manager and the right-hand side is the expected gain from renegotiation with an optimistic manager. The intuition is equivalent to the classic lemons problem analyzed by Akerlof (1970). Although there are gains from trade when the manager "sells" his long-term compensation for short-term compensation, pessimistic managers are more eager to sell, since they know that the long-term payment is a lemon. Therefore, the market for optimistic managers breaks down. Substituting $t_{2}^{\prime}(R, H)=t_{2}(R), t_{1}^{\prime}(L)=\lambda t_{2}(R) P(R \mid L, W)$, and $t_{1}^{\prime \prime}(H)=\lambda t_{2}(R, H) P(R \mid H, W)$ in the expression above, the vesting contract is renegotiation proof if and only if

$$
\frac{1-\lambda}{\lambda} \leq \frac{P(L \mid W)}{P(H \mid W)}\left(1-\frac{P(R \mid L, W)}{P(R \mid H, W)}\right) .
$$

The renegotiation proofness Condition (15) states that the adverse selection problem has to be sufficiently big to overcome the gains from trade. The lefthand side shows that it is easier to provide long-term incentives if the manager is patient ( $\lambda$ high) so that the gains from accelerating payments is smaller. The first term on the right-hand side is the fraction of pessimistic over optimistic managers present at the renegotiation. The larger this fraction is, the easier it is to stick to the long-term contract, since the investor is more likely to deal with a pessimistic manager that he loses out to in the renegotiation. The expression in brackets captures the difference in expectation about the longterm pay between optimistic and pessimistic managers: If managers receiving a low signal in period 1 have the same expectation about high profits in period 2 as managers receiving a high signal, it is impossible to separate managers, and the contract will be renegotiated. If the early signal contains information, then screening high and low signals is possible. 
The following claim shows that any renegotiation-proof long-term contract must be in the form of the vesting contract outlined above.

Claim 1. Any long-term contract that pays when $y=R$ has to be in the form of a vesting contract $\left\{t_{1}(L), t_{2}(R, H)\right\}$, where

$$
t_{1}(L)=\lambda P(R \mid L, W) t_{2}(R, H)
$$

and $t_{2}(R, H)>0$. This is renegotiation proof if and only if Condition (15) holds.

Proof. See Appendix A.

An essential feature of this contract is that it gives the manager discretion to choose when he wants to take his payment. One way to implement the contract is to award the manager stock options. Suppose there is one stock that is entitled to the gross profit of the company, and the manager gets an option on a fraction $k$ of this stock at exercise price $X$ per stock. The stock price $S_{t}$ is given by

$$
\begin{aligned}
S_{1} & =E(y \mid W)=P(R \mid W) R, \\
S_{2}(R) & =R, S_{2}(0)=0 .
\end{aligned}
$$

To replicate the long-term payoff of optimistic managers, we should set $k$ and $X$ so that

$$
k\left(S_{2}(R)-X\right)=t_{2}(R, H),
$$

and to replicate the short-term payoff of pessimistic managers, we should set

$$
k\left(S_{1}-X\right)=\lambda P(R \mid L, W) t_{2}(R, H),
$$

which gives

$$
X=R \frac{P(R \mid W)-\lambda P(R \mid L, W)}{1-\lambda P(R \mid L, W)}
$$

and

$$
k=\frac{t_{2}(R, H)}{R\left(\frac{1-P(R \mid W)}{1-\lambda P(R \mid L, W)}\right)} .
$$

There are other ways that firms can give managers discretion to choose the maturity of their compensation. One way is to award restricted stocks at the outset, with a vesting schedule that specifies when the stocks can be sold. The options contract has one more instrument, the exercise price, that can be used to fine-tune incentives. Because of this, it can be shown that restricted stocks do not fully replicate the optimal contract in our setting. Another alternative 
that is commonly used is to allow managers to forgo their current pay or bonus for future payments. Such deferred compensation plans with the appropriate choice of bonuses is another way of implementing the optimal contract above.

Whether it is feasible to induce effort with the vesting contract depends on the cost to the investor. The lowest cost to the investor for making the manager work with a pure vesting contract can be calculated from the moral-hazard constraint:

$$
P(L \mid W) t_{1}(L)+\lambda P(H \mid W) P(R \mid H, W) t_{2}(R, H)-d \geq t_{1}(L) .
$$

The left-hand side is the expected payoff from working. The first term is the case where a manager who works gets a low signal and takes the early payment. The second is the case where the manager gets a high signal and takes the late payment. The right-hand side is the manager's payoff from shirking, in which case he always takes the early payment. Using Claim 1 we can substitute $\lambda P(R \mid L, W) t_{2}(R, H)$ for $t_{1}(L)$ in the moral-hazard condition above, and then solve for the lowest $t_{2}(R, H)$ that satisfies the condition. The lowest expected cost to the investor can then be calculated as

$$
\begin{aligned}
c_{v} & \equiv P(L \mid W) P(R \mid L, W) t_{2}(R, H)+P(H \mid W) P(R \mid H, W) t_{2}(R, H) \\
& =\frac{d}{1-\frac{(1-\lambda) \theta}{\theta+\lambda(1-\theta)}-\lambda\left(\frac{1}{\theta+\lambda(1-\theta)}\right) \frac{(1-\theta)}{P(L \mid W)}} .
\end{aligned}
$$

The cost of the optimal vesting contract over and above the first best cost $d$ now derives from two sources. First, optimistic managers are paid late, which is costly because of the discount parameter $\lambda$. Second, managers earn a rent even when shirking, since they can still get the early pay by exercising the option.

If this cost is smaller than the expected payoff $p R-1$ to the investor, and the renegotiation proofness Condition (15) also holds, then a long-term vesting contract is optimal. Since the manager has all the ex ante bargaining power, the investor's break-even constraint must bind at the optimal contract. The simplest way to achieve this is to make an extra lump-sum transfer of $t_{1}=p R-1-c_{v}$ to the manager in period 1. If either $p R-1<c_{v}$ or Condition (15) does not hold, then it is impossible to implement high effort with zero transparency. We collect these results in the following proposition.

Proposition 2. With zero transparency, if $p R-1 \geq c_{v}$ and Condition (15) holds, the optimal contract consists of a vesting contract $\left\{t_{1}(L), t_{2}(R, H)\right\}$ plus a short-term payment $t_{1}=c_{v}-(p R-1)$. If $p R-1<c_{v}$ or Condition (15) does not hold, the project cannot be implemented.

In the full-commitment benchmark, we showed that increasing transparency increases welfare by expanding feasible contracting instruments. We now show that without full commitment, increasing transparency can decrease welfare as 
it reduces feasible contracting instruments. The reason is that when contracts have to be renegotiation proof, full transparency eliminates the possibility of using a long-term contract. If short-term contracts do not implement high effort, then full transparency eliminates the possibility of contracting altogether. However, long-term vesting contracts can be renegotiation proof with zero transparency. So, it is possible that a long-term renegotiation-proof contract with zero transparency implements full effort but that a short-term contract with full transparency does not.

Proposition 3. If $p<\frac{1}{2}$, there is always a profit $R$ and level of impatience $\underline{\lambda}<1$, such that if $\lambda \geq \underline{\lambda}$, the solution with zero transparency is feasible but the solution with full transparency is not.

\section{Proof. See Appendix B.}

\section{Paying for Luck and Limits to Relative Performance Evaluation}

As we discussed above, in the full-commitment case there is no reason to tie the manager's compensation to variables such as general industry conditions that are independent of his effort but may affect profits. Still, almost all compensation contracts observed in reality are tied to absolute performance measures such as the firm's profits or stock price that to a large extent depend on "luck" outside the control of the manager. This has puzzled economists since it is usually rather easy to remove some of these variables from the compensation contract by, for example, rewarding managers only to the extent that they overperform industry benchmarks. We now show that when contracts have to be renegotiation proof, rewarding managers for luck can be optimal. The intuition is straightforward: In order to make long-term payments renegotiation proof, managers must have private information in the short term that make them differentially optimistic about the long-term pay. If long-term compensation is based on a measure that is perfectly correlated with effort, this is not possible.

To see this, suppose that we set $p=1$, so that a manager who works knows for sure that profits in period 2 will be high. Then, as can be seen from Condition (15), it is impossible to make the long-term payment renegotiation proof. This is because even a manager who gets a negative signal in period 1 knows that, if he has worked, his option will pay off in period 2. Thus, there is really no asymmetric information about the future profits, and nothing preventing the principal from renegotiating to a short-term pay. If short-term signals are noisy, then short-term contracts will not implement high effort.

Now, maintain the assumption that $p=1$, but suppose that profits are also affected by the state of the industry in period 2. Profits are $y+s$ where $s \in$ $\{R, 0\}$ denotes the part of profits that is affected by industry conditions that are completely out of the manager's control. Also, suppose that managers privately learn the state of the industry in period 1, while the principal only learns it in 
period 2. Suppose also that the contract pays $t_{2}$ only if profits are $2 R$, that is, if the state of the industry is good and the manager has worked hard. It is easy to show that such a contract is renegotiation proof if and only if

$$
(1-\lambda) t_{2} \operatorname{Prob}(y+s=2 R) \leq \lambda t_{2}(1-\operatorname{Prob}(y+s=2 R)) .
$$

The left-hand side is the expected gain from renegotiating in period 1 to a short-term payment $t_{1}^{\prime}=\lambda t_{2}$ with managers who know the industry will be in the good state. The right-hand side is the loss from this renegotiation to pessimistic managers, who get an early payment worth $\lambda t_{2}$ instead of a longterm payment worth zero. The expected cost to the principal of making the agent work with such a long-term contract is then $t_{2} \operatorname{Prob}(y+s=2 R)$, which from the moral-hazard condition has to be set such that

$$
\lambda t_{2} \operatorname{Prob}(y+s=2 R)-d \geq 0 .
$$

Here, the left-hand side is the manager's expected utility from working and the right-hand side his expected utility from shirking. Setting this to an equality, we see that the expected cost to make the manager work with this contract is $d / \lambda$, the same as the cost in the full-commitment model. Thus, tying the manager's compensation to the total profits of the firm instead of using relative performance evaluation is optimal.

There is a broader message here. In a full-commitment model, it is always optimal to tie the manager's compensation to a measure that is as closely correlated to his effort as possible and removes any noise that is outside the control of the manager. But in the extreme, such a measure is so clean that under the equilibrium effort, there is no uncertainty about the outcome, and hence nothing preventing renegotiation. Paradoxically, this destroys the contractibility of such a signal. Contracts should therefore tie compensation not only to a measure that is related to effort, but also to measures about which the manager is likely to have better information than the market but that are stochastic (outside the control of the manager). An obvious candidate is to simply tie the manager's compensation to the total profit of the company.

\section{The Optimal Amount of Transparency and Earnings Smoothing}

We have shown that zero transparency can dominate full transparency. Lower transparency has the advantage that it can make long-term contracts renegotiation proof, but has the disadvantage that a shirking manager always earns rents by cashing out his option early. If we can increase transparency without violating the renegotiation condition, contracts become more efficient. In this section, we show how the optimal amount of transparency can be induced by a compensation package that endogenously encourages the manager to engage in the right amount of earnings smoothing. The idea is that the higher the earnings 
target is, the harder it is for pessimistic manager to reach it, so the greater is the level of transparency.

To this end, we slightly modify the model so that the earnings observed by investors can take on values in a continuous interval. Denote by $\phi$ the earnings observed by investors in period 1 , and assume that $\phi \in[l, h]$. If the manager does not manipulate, the signal the investor receives fully reveals the manager's profit forecast: $\phi=l$ if $\sigma=L$, and $\phi=h$ if $\sigma=H$. A high earnings signal can be freely manipulated downward to any $\phi<h$, while a low earnings signal can be manipulated upward with some probability. We view this asymmetry between understating and overstating earnings as realistic. For example, it may not be very difficult to omit or postpone the reporting of some orders to lower an initial high earnings signal, but it is probably harder to fabricate false orders without detection. ${ }^{15}$

We denote the likelihood that pessimistic managers can state earnings $\phi$ by $m(\phi)$, and assume that $m(\phi)$ is strictly decreasing and continuous in $\phi$, with $m(l)=1$ and $m(h) \geq 0$. Hence, it is less likely that a pessimistic manager is able to produce a bigger overstatement. If the manipulation fails, the pessimistic manager reports earnings $l$.

The difference with the zero transparency case is that the contract can now be contingent on the earnings $\phi$ observed by investors. A contract is now a set of transfers

$$
t=\left\{t_{1}(\phi, r), t_{2}(\phi, y, r)\right\}_{\phi \in[l, h], y \in\{0, R\}, r \in\{L, H\}} .
$$

The derivation of the optimal contract follows the same logic as for the zero transparency case. The biggest difference is that the contract has to induce managers to try to hit an earnings target $\phi^{*}$, which is chosen appropriately to make long-term compensation renegotiation proof. In particular, suppose the contract has the following two components:

- A short-term bonus $t_{1}$, which is rewarded if and only if earnings reach the target $\phi^{*}$.

- A vesting contract $\left\{t_{1}\left(\phi^{*}, L\right), t_{2}\left(\phi^{*}, R, H\right)\right\}$, which is also rewarded if and only if earnings reach the target $\phi^{*}$, where

$$
t_{1}\left(\phi^{*}, L\right)=\lambda P(R \mid L) t_{2}\left(\phi^{*}, R, H\right) .
$$

Given this contract, optimistic managers will reduce their privately observed high signal to $\phi^{*}$ in period 1 , and choose to wait until period 2 to exercise their option. Pessimistic managers will try to increase their privately observed low signal to $\phi^{*}$, and succeed with probability $m\left(\phi^{*}\right)$. If they succeed, they exercise

15 We assume that manipulation has no effect on the long-term profit signal. We view manipulation as a way to temporarily mislead investors, but eventually the true state of the company will be revealed. This captures salient features of the financial scandals at Enron and WorldCom where managers succeeded in hiding information in the short term but the firms' fundamentals became clear eventually. 
the option early. The benefit of this contract relative to the zero transparency case is that it reduces the probability of a reward to a pessimistic manager from 1 to $m\left(\phi^{*}\right)$, which makes it easier to provide ex ante incentives. We can interpret $1-m\left(\phi^{*}\right)$, the probability that the pessimistic manager fails to manipulate, as the level of transparency induced by an earnings target $\phi^{*}$.

In fact, it may even be possible to provide incentives with a pure short-term contract as there is now some information in period 1 , so we start by deriving the cost to the investor of inducing effort this way. In a short-term contract with manipulation, the manager gets paid if the first-period report is $\phi^{*}$, and there are no period 2 transfers. From the moral-hazard constraint, we can calculate the expected cost $c_{S}\left(\phi^{*}\right) \equiv P\left(\phi^{*} \mid W\right) t_{1}\left(\phi^{*}\right)$ to the investor of giving the manager the incentive to work with this contract as

$$
c_{s} \equiv P\left(\phi^{*} \mid W\right) t_{1}(H)=\frac{d}{1-\frac{P(H \mid S)+m\left(\phi^{*}\right) P(L \mid S)}{P(H \mid W)+m\left(\phi^{*}\right) P(L \mid W)}} .
$$

As $P(L \mid S)>P(L \mid W)$, this is decreasing in $\phi^{*}$. Hence, it is optimal to set transparency as high as possible at $1-m(h)$ through a maximal earnings target $\phi^{*}=h$ to minimize the efficiency wage. This is intuitive since there is no renegotiation of a short-term contract and hence no benefit of intransparency. Again, as in the case of full commitment, if such a short-term contract is feasible (i.e., costs less than $p R-1$ ), it is optimal as it maximizes social surplus by paying the manager only in period 1 .

We now derive the cost of inducing effort with a pure long-term vesting contract, and the optimal amount of transparency when such a contract is used. The vesting contract will be renegotiation proof if and only if

$$
\frac{1-\lambda}{\lambda} \leq \frac{m\left(\phi^{*}\right) P(L \mid W)}{P(H \mid W)}\left(1-\frac{P(R \mid L, W)}{P(R \mid H, W)}\right) .
$$

This is derived in exactly the same way as Condition (15) from our earlier model with full manipulation, except that the probability of renegotiating with a pessimistic manager after seeing earnings statement $\phi^{*}$ is now changed to $m\left(\phi^{*}\right) P(L \mid W)$ instead of $P(L \mid W)$. Note that the lower the earnings target is, the easier it is to make the renegotiation condition hold. This is because when the earnings target is low, more pessimistic managers will succeed in reaching it, which makes the adverse selection problem worse for the investor if he would try to renegotiate to a short-term payment.

Given an earnings target $\phi^{*}$, the lowest cost $c_{v}\left(\phi^{*}\right)$ of inducing high effort with a pure vesting contract can be calculated from the moral-hazard constraint as

$$
c_{v}\left(\phi^{*}\right) \equiv \frac{d}{1-\frac{(1-\lambda) \theta}{\theta+\lambda m\left(\phi^{*}\right)(1-\theta)}-\lambda\left(\frac{(1-\theta)+m\left(\phi^{*}\right) \theta}{\theta+\lambda m\left(\phi^{*}\right)(1-\theta)}\right) \frac{(1-\theta)}{P(L \mid W)}} .
$$


It is easy to show that the cost is decreasing in the transparency $1-m\left(\phi^{*}\right)$. Therefore, if a long-term vesting contract is used, the earnings target $\phi^{*}$ should be set maximal subject to the renegotiation condition not being violated,

$$
m\left(\phi^{*}\right)=\frac{\lambda}{1-\lambda} \frac{1}{\frac{P(L \mid W)}{P(H \mid W)}\left(1-\frac{P(R \mid L, W)}{P(R \mid H, W)}\right)} .
$$

We call the target that solves (30) the optimal earnings target and note that it is typically below the maximal value, so the contract will endogenously create incentives to smooth earnings in order to reduce transparency.

If a short-term contract with manipulation and maximal transparency $1-$ $m(h)$ is not feasible while the vesting contract with the optimal earnings target $\phi^{*}$ that solves (30) is, a long-term vesting contract with earnings smoothing is optimal. We collect these results in the next proposition.

Proposition 4. If a short-term contract with manipulation is feasible, then at the optimal contract $t_{1}(h)>0$ and all other payments are zero. The optimal transparency is maximal at $1-m(h)$. If it is not feasible but $p R-1 \geq c_{v}\left(\phi^{*}\right)$ where $\phi^{*}$ is given from Expression (30), a long-term vesting contract with earnings smoothing is optimal. The optimal contract then consists of a shortterm bonus $t_{1}$ and a vesting contract $\left\{t_{1}\left(\phi^{*}, L\right), t_{2}\left(\phi^{*}, R, H\right)\right\}$, both of which are awarded if and only if period 1 earnings reach the optimal earnings target $\phi^{*}$.

The now familiar logic implies that full transparency can be dominated by allowing earnings manipulation.

Proposition 5. There always exists a profit $R$ and $a \underline{\lambda}<1$ such that, for all $\lambda \geq \underline{\lambda}$, the project cannot be implemented under full transparency but can be implemented with the optimal amount of transparency.

Proof. See Appendix C.

Note that this is a stronger result than Proposition 3, where we compared full transparency to zero transparency. When transparency can be set optimally, there is always a range of $\lambda$ such that it is easier to find a feasible solution with some manipulation than with full transparency.

Although we interpret $m\left(\phi^{*}\right)$ as the ease of manipulating earnings upwards to the target $\phi^{*}$, we can almost equivalently think of it as any exogenous measure of the extent to which the information of the manager is private. For example, suppose an auditor seeks to find if there is any bad information about the firm's earnings. If the manager sees an $H$ signal, the auditor cannot find any such information, and hence investors also see an $H$ signal. But when the manager sees an $L$ signal, the auditor discovers it with probability $1-m$ and investors 
then see an $L$. In this model, the renegotiation Condition (28), the expressions for the costs $c_{s}$ and $c_{v}$, and the optimal transparency derived in Expression (30) would then be unchanged if we substitute $m$ for $m\left(\phi^{*}\right)$.

We have emphasized the role compensation contracts have in influencing the degree of transparency, either by making bonus schedules more or less high-powered to encourage the right amount of earnings smoothing as in this section, or by the choice of relative versus absolute performance contracts as in Section 4 above. However, we can think of several other ways in which a firm can influence the degree of transparency.

Frequency of reporting. Whether a firm chooses to release weekly, quarterly, or annual reports should also affect the contracting environment between investors and managers. Our model suggests that there is an optimal reporting frequency. If reporting is very frequent, there will be very little information asymmetry between managers and investors to prevent renegotiation. On the other hand, if reports are very infrequent, the loss in liquidity provision to the manager may be substantial.

Choice between being a public or a private firm. Firms can commit to more precise reporting by listing on a public stock exchange, which should increase transparency. Also, firms can choose to cross-list in countries where reporting requirements are higher.

Ownership structure and investor monitoring. The transparency between managers and investors increases when investors monitor the firm more closely. There are several ways in which a firm can influence the degree of investor monitoring. The more concentrated ownership a firm has, the more incentive the investor has to monitor. Also, the structure of the securities an investor holds affects his incentive to monitor. The more information sensitive a security is, the higher the incentive to monitor. Thus, a firm can concentrate the information sensitivity by having more leverage. An extreme example of monitoring incentives is when a firm goes through an LBO in which a buyout fund has a very concentrated ownership of highly levered equity. An extreme example of low incentives to monitor is when a firm has a dispersed ownership structure and little leverage.

\section{Discussion}

\subsection{Comparative statics and empirical implications}

We now describe the comparative statics of the model in Section 5 and use them to discuss empirical implications. We derive the comparative statics in Appendix D, and summarize them in Table 1. By "degree of transparency" we will mean the probability $1-m$ that a pessimistic manager's signal is revealed to investors. We can either think of $1-m$ as being optimally chosen as in Proposition 4 above, or as being a given parameter that is not necessarily at the optimal level (e.g., reflecting the current state of the accounting technology). 
Table 1

Comparative statics

\begin{tabular}{lccc} 
& $\begin{array}{c}\text { Cost } \\
\text { Long-term vesting }\end{array}$ & $\begin{array}{c}\text { Cost } \\
\text { Short term }\end{array}$ & $\begin{array}{c}\text { Optimal transparency } \\
\left(1-m\left(\phi^{*}\right)\right)\end{array}$ \\
\hline Given transparency $(1-m)$ & - & - & n.a. \\
Patience $(\lambda)$ & - & 0 & + \\
Link effort - period 2 signal $(p)$ & + & - & - \\
Internal information $(\theta)$ & - & - & + \\
\hline
\end{tabular}

The first two columns of Table 1 show how the cost to the principal of inducing high effort through a long-term and a short-term contract changes with the parameters. When transparency is given, this is just the direct effect of changing parameters on the $\operatorname{costs} c_{v}$ and $c_{s}$ derived above. When transparency is picked optimally, there will also be an indirect effect, since the optimal transparency $1-m\left(\phi^{*}\right)$ will also change with the parameters of the model. The qualitative nature of the comparative statics does not change depending on whether transparency is given or is picked optimally, so we do not make a distinction in the table.

The last column of Table 1 shows how the optimal transparency changes with other parameters of the model when it can be picked freely using one of the channels described above.

The first row of Table 1 shows how contracting costs are affected by a change in transparency when it is not picked optimally. Both long- and shortterm contracting become cheaper with increased transparency, but it becomes harder to make long-term contracts renegotiation proof. Therefore, the model suggests that increased transparency leads to more short-term contracting. Thus, where the scope for private information is smaller, firms should have shorter maturity of compensation, as should public firms where reporting requirements are higher. A firm with timely, nonmanipulable cash flows, such as a utility, is therefore more likely to have short-term compensation and less likely to rely on options contracts. In countries where accounting technology is worse, firms should rely more on long-term contracting.

The second row of Table 1 shows the comparative statics with respect to the discount parameter $\lambda$. As $\lambda$ increases, long-term contracting becomes cheaper for two reasons. First, since the manager is less impatient, he values the longterm payment more. Second, it is easier to make long-term payments renegotiation proof, which means that the optimal transparency and hence the payperformance sensitivity can be increased. We can interpret $\lambda$ in two ways. First, it is a measure of the time-lag between effort and outcomes. For firms that rely more on R\&D and long-term strategic investments, $\lambda$ is smaller. Second, we interpret impatience as a reduced form of risk aversion. Managers are typically more risk averse than investors because they are subject to the idiosyncratic risk of the firm. This gives an incentive to renegotiate late payments to safe early payments in much the same way as managerial impatience. With this interpretation, $\lambda$ is smaller for firms where cash flows are riskier. Therefore, 
ceteris paribus, transparency should be set lower (by, for example, using bonus schedules that encourage more earnings smoothing) for riskier firms and more R\&D-intensive firms, and these type of firms should also rely less on long-term contracting. ${ }^{16}$

The parameter $p$ is a measure of the predictability of the link between the manager's effort and the long-term signal. The more predictable this outcome is, the less room there is for asymmetric information in the short term. This has a direct effect on the cost of long-term contracting, because managers who receive the low short-term signal are relatively less pessimistic when $p$ is high, and hence earn more when cashing out in the renegotiation-proof contract. It also has an indirect effect in that as $p$ goes up, optimal transparency goes down because it is harder to make long-term payments renegotiation proof. Therefore, for a firm where the link between observables and effort is very tight, it is beneficial to either have a low level of transparency, or tie the compensation of the manager to some measure that has more noise and that the manager has information about.

The last row of Table 1 derives the comparative statics with respect to $\theta$, which measures the precision of the soft information that is available to managers but not necessarily directly to investors. Both long- and short-term contracting become cheaper as the precision of the internal signal goes up. This is because, even for a given level of transparency, as $\theta$ increases, the earnings measure observed by investors in period 1 becomes more informative, which makes it cheaper to provide incentives. This is true even for long-term contracting, since the option is only rewarded if high earnings are observed. Further, as $\theta$ goes up, there is more information asymmetry between insiders and outsiders, which means that transparency can be increased without violating the renegotiation constraint. This further increases the pay-for-performance sensitivity. In sum, the model suggests that it is always beneficial to make the internal information as precise as possible as long as enough of the information is hidden from outsiders.

Finally, the model has implications for how stock returns, earnings restatements, and exercise behavior of executives should be related. Our model suggests that it is a bad signal when a manager exercises stock options early. Therefore, subsequent returns should be low. Further, early exercise should be more prevalent in periods after which firms had to issue earnings restatements. These predictions are supported in the empirical literature. Burns and Kedia (2006) find that firms in which managers have more option compensation are more likely to misreport earnings, and exercise options more aggressively in years where earnings are misreported. They do not find similar patterns for restricted stock incentives. This is consistent with our model, since firms that

16 However, we have to be careful what we mean by "long term" when mapping the model into data; R\&D effort, for example, may also take quite long to perform, so the compensation might come relatively far out in the future, but will not be based on the final information. 
need to introduce the highest level of manipulation also need to award stock options to managers. Burns and Kedia (2008) also show that managers who overstate earnings deliberately also exercise more options, and do not retain the stock after exercise. Bartov and Mohanram (2004) also find similar evidence.

\subsection{Implications for regulation}

An obvious takeaway from our model is that regulation that makes full transparency unavoidable is potentially harmful. The main goal of the Sarbanes-Oxley Act of 2002 was in fact to make financial reporting more reliable, and to make managers, boards, and accountants more accountable for misreporting. To the extent that firms cannot contract around these measures to create the optimal amount of information asymmetry, this can destroy value. An empirical prediction of our model is that executive compensation programs for public companies should have become more short term as a result. Further, more companies should have chosen to go private to avoid the negative effects of the legislation. Another prediction is that if manipulation has become harder, firms may now need to set performance targets lower to induce the right amount of opaqueness.

However, regulation that makes manipulation harder can also have positive effects in our model. For firms that already use short-term contracts, manipulation has no benefit. Further, to the extent that manipulation is made harder but contracts can respond to make the long-term component renegotiation proof, the downside effects on long-term contracts are reduced. Therefore, for this type of regulation to be beneficial, it is critical that it is not accompanied by regulations that restrict the possibilities of contracting.

We could also imagine that regulation, or a general shift to a better accounting technology, can increase $\theta$, the informativeness of the short-term signal. This has a purely positive effect on both long- and short-term contracts as long as enough of the short-term information is still hidden to the principal. Here, the empirical predictions about whether firms will gravitate to more or less long-term contracting is ambiguous.

\subsection{Model extensions and limitations}

6.3.1 Repeated effort. An important ingredient of the model is that renegotiation takes place after the effort of the manager is sunk. If the manager would continue to work after the renegotiation stage, the temptation to provide him with liquidity will be muted by the necessity to give him further incentives to work. In a strict sense, our model therefore might apply best to situations where the manager is expected to quit, retire, or switch tasks. However, even if he continues to work on the same task, some of the effort will be sunk and so there is still an ex post incentive to modify the ex ante contract in the direction of providing more liquidity. Thus, many of the qualitative results we derive should not be sensitive to the (extreme) assumption of a completely sunk effort. 
Further, when renegotiation can take place before all the effort is sunk, other commitment problems appear. As pointed out by, among others, Acharya, John, and Sundaram (2000), it is often optimal ex post to provide fresh incentives to a manager even after a bad initial performance. This can destroy ex ante incentives, as the manager knows that he will be given a valuable new compensation package even if he shirks in the first period. Therefore, introducing asymmetric information through manipulation might be helpful in preventing this type of renegotiation as well. We leave for future research the interesting but probably complicated analysis of a full dynamic effort model with renegotiation.

6.3.2 Repeated manipulation. For simplicity, we have also chosen to consider manipulation only of the first-period earnings. If a manager can report earnings dynamically, and is capable of pushing off the booking of earnings today to a future date, or book earnings today that are expected to occur in the future, we conjecture that contracts would look largely similar to those we have derived. In particular, a bonus schedule with a minimum and maximum threshold would give the manager an incentive to smooth earnings over time, thereby reducing the informational content of the accounts. Again, a full dynamic model is beyond the scope of this paper.

\section{Conclusion}

We have set up a model of optimal executive compensation with renegotiation when managers are more impatient than investors. We have shown that compensating the manager based on long-term information, even when it is much more informative than short-term information, is impossible if there is not enough opaqueness in the short term. This is because after effort is sunk, investors always have an incentive to renegotiate any long-term contract when the manager is impatient. Only if there is enough private information early on can a long-term contract be credible. The private information creates a lemons problem at the renegotiation stage, which can destroy the market for renegotiation. We show that allowing the manager to manipulate short-term earnings can be beneficial. The features of the compensation contract should be set to induce the manager to create just enough misinformation such that renegotiation is not optimal ex post. Our optimal contracts have the following features:

- The long-term portion of contracts can be viewed as a stock option that the manager has the right to exercise early. He does so if he feels the firm is overvalued.

- It is often optimal to make the manager's compensation depend on variables that he has no influence over, such as the general state of the industry.

- The short-term portion of contracts can be viewed as a bonus that is awarded only if a certain earning threshold is reached, with no additional payment if earnings are above the threshold. This encourages managers 
to smooth earnings: Optimistic managers understate earnings while pessimistic managers overstate them.

These results seem to conform well with observed practices in executive compensation.

Although we study manipulation as a source of asymmetric information, the logic extends to other dimensions of transparency that the firm can influence. One example is the choice of going public, with the extra demands on accounting and extra scrutiny from stock markets it entails. Another way is to design the securities that investors hold in a way that induces the right amount of monitoring. Arm's-length public debt would induce the least monitoring and thus the least transparency, while equity held by an active investor such as a venture capitalist would induce the most intense monitoring (see Rajan 1992 and Aghion, Bolton, and Tirole 2004 for related models).

\section{Appendix}

\section{A: Proof of Claim 1}

The contract $t=\left\{t_{1}(r), t_{2}(y, r)\right\}_{y \in\{0, R\}, r \in\{L, H\}}$ is renegotiation proof for high effort if and only if it is the solution to the program

$$
\min _{\left\{t_{1}^{\prime}(r), t_{2}^{\prime}(y, r)\right\}_{y \in\{0, R\}, r \in\{L, H\}}} E\left(t_{1}^{\prime}(r)+t_{2}^{\prime}(y, r) \mid W\right),
$$

such that

$$
\begin{aligned}
& t_{1}^{\prime}(H)+\lambda\left(P(R \mid H, W) t_{2}^{\prime}(R, H)+P(0 \mid H, W) t_{2}^{\prime}(0, H)\right) \\
& \geq t_{1}^{\prime}(L)+\lambda\left(P(R \mid H, W) t_{2}^{\prime}(R, L)+P(0 \mid H, W) t_{2}^{\prime}(0, L)\right) \\
& t_{1}^{\prime}(L)+\lambda\left(P(R \mid L, W) t_{2}^{\prime}(R, L)+P(0 \mid L, W) t_{2}^{\prime}(0, L)\right) \\
& \geq t_{1}^{\prime}(H)+\lambda\left(P(R \mid L, W) t_{2}^{\prime}(R, H)+P(0 \mid L, W) t_{2}^{\prime}(0, H)\right) \\
& t_{1}^{\prime}(H)+\lambda\left(P(R \mid H, W) t_{2}^{\prime}(R, H)+P(0 \mid H, W) t_{2}^{\prime}(0, H)\right) \\
& \geq t_{1}(H)+\lambda\left(P(R \mid H, W) t_{2}(R, H)+P(0 \mid H, W) t_{2}(0, H)\right) \\
& t_{1}^{\prime}(L)+\lambda\left(P(R \mid L, W) t_{2}^{\prime}(R, L)+P(0 \mid L, W) t_{2}^{\prime}(0, L)\right) \\
& \geq t_{1}(L)+\lambda\left(P(R \mid L, W) t_{2}(R, L)+P(0 \mid L, W) t_{2}(0, L)\right) \\
& t_{1}^{\prime}(r), t_{2}^{\prime}(y, r) \geq 0 \quad \forall r, y .
\end{aligned}
$$

The incentive compatibility (IC) condition ensures that managers self-select into the right contract on the menu. By the Revelation Principle, we can restrict attention to contracts such that it is incentive compatible for the manager to reveal his true signal $\sigma$ in his report. The individual rationality (IR) constraint ensures that the manager is no worse off under the new contract $t^{\prime}$ than under the old contract $t$. Finally, LL is the limited liability constraint of the manager. If the old contract solves this program, it means that there is no way to make both the manager and the investor better off with a new contract. We now characterize renegotiation-proof long-term contracts. We restrict attention to contracts that can have $t_{2}(R, \sigma)>0$ for some $\sigma$. It is easy to show that a long-term contract that pays only for low profits can never implement high effort. 
Lemma 1. The contract $t$ is renegotiation proof if and only if $t_{1}(L), t_{1}(H), t_{2}(R, H) \geq 0$ and all other payments are zero, where

$$
t_{1}(L)=t_{1}(H)+\lambda P(R \mid L) t_{2}(R, H),
$$

and $t_{2}(R, H)>0$ if and only if

$$
\frac{1-\lambda}{\lambda} \leq \frac{P(L \mid W)}{P(H \mid W)}\left(1-\frac{P(R \mid L, W)}{P(R \mid H, W)}\right) .
$$

\section{A.1. Proof of Lemma 1}

Claim 2. In a renegotiation-proof contract, it is optimal to set $t_{2}(R, L)=0$.

Proof. Suppose $t_{2}(R, L)>0$. Then, lower $t_{2}(R, L)$ and increase $t_{1}(L)$ to keep the lefthand side of $I C L$ and $I R L$ constant. This lowers the $R H S$ of $I C H$ as $P(R \mid H, W)>$ $P(R \mid L, W)$, and leaves all other constraints unchanged. This decreases the minimand as $\lambda<1$, a contradiction.

Claim 3. In a renegotiation-proof contract, it is optimal to set $t_{2}(0, H)=0$.

Proof. Otherwise, lower $t_{2}(0, H)$ and increase $t_{1}(H)$ to keep the left-hand side of $I C H$ and I RH constant. This relaxes $I C L$ as $1-P(R \mid H, W)<1-P(R \mid L, W)$. As $P(H \mid W)>0$, this strictly decreases the minimand as $\lambda<1$, a contradiction.

Claim 4. Suppose $t_{2}(R, H)>0$ in a renegotiation-proof contract. Then, $t_{2}(0, L)=0$ and $t_{1}(L)=$ $t_{1}(H)+\lambda P(R \mid L) t_{2}(R, H)$.

Proof. First, we show that if $t_{2}(R, H)>0, I C L$ must bind. Suppose to the contrary that $I C L$ is slack and $t_{2}(R, H)>0$. Then, lower $t_{2}(R, H)$ and increase $t_{1}(H)$ to keep the left-hand side of $I C H$ and $I R H$ constant. This decreases the minimand since $\lambda<1$, and does not violate ICL since it is slack. Thus, $I C L$ must bind. But then, $I C H$ must be slack, since

$$
\begin{aligned}
& t_{1}(H)+\lambda P(R \mid H, W) t_{2}(R, H) \\
> & t_{1}(H)+\lambda P(R \mid L, W) t_{2}(R, H) \\
= & t_{1}(L)+\lambda P(0 \mid L, W) t_{2}(0, L) \\
\geq & t_{1}(L)+\lambda P(0 \mid H, W) t_{2}(0, L),
\end{aligned}
$$

where the first inequality follows from $P(R \mid H, W)>P(R \mid L, W)$ and the last from $P(0 \mid L, W)>$ $P(0 \mid H, W)$. Therefore, $I C H$ can be omitted from the program. Now we show that $t_{2}(0, L)=0$. Otherwise, lower $t_{2}(0, L)$ and increase $t_{1}(L)$ to keep the left-hand side of $I C L$ constant. This weakly decreases the minimand and violates no constraints ( $I C H$ already having been shown redundant). From the binding $I C L$ constraint, we therefore have $t_{1}^{\prime}(L)=t_{1}(H)+\lambda P(R \mid L) t_{2}(R, H)$.

We now establish the last part of the lemma.

Claim 5. If the manager works at time $0, t_{2}(R, H)>0$ is renegotiation proof if and only if Condition (A2) holds.

Proof. Suppose $t_{2}(R, H)>0$. Then, any perturbation that increases $t_{2}(R, H)$ and reduces $t_{1}(H)$ while satisfying $I C L, I R L$, and $I R H$ cannot increase the lender's payoff as $\lambda<1$. Hence, the 
only possible gain is if $t_{2}(R, H)$ is lowered and $t_{1}(H)$ is increased. Such a perturbation that keeps the right-hand side of $I C L$ constant lowers the left-hand side of $I R H$, and hence cannot be feasible. Therefore, lower $t_{2}(R, H)$ and increase $t_{1}(H)$ to keep the left-hand side of $I R H$ constant. The change in the objective function is

$$
\begin{aligned}
P(H \mid W)(\lambda P(R \mid H, W) & -P(R \mid H, W)) \\
& +P(L \mid W) \lambda(P(R \mid H, W)-P(R \mid L, W)) \\
= & P(L \mid W) \lambda(P(R \mid H, W)-P(R \mid L, W)) \\
& -P(H \mid W)(1-\lambda) P(R \mid H, W) .
\end{aligned}
$$

The expression above has the same sign as

$$
\frac{P(L \mid W)}{P(H \mid W)}\left(1-\frac{P(R \mid L, W)}{P(R \mid H, W)}\right)-\frac{1-\lambda}{\lambda} .
$$

This is negative if and only if Condition (A2) does not hold, in which case the minimand is decreased and $t_{2}(R, H)>0$ cannot be renegotiation proof. Thus, $t_{2}(R, H)>0$ is renegotiation proof if and only if Condition (A2) holds.

This concludes the proof of the lemma and Claim 1.

\section{B: Proof of Proposition 3}

Notice that the right-hand side of Condition (15) is

$$
\frac{P(L \mid W)}{P(H \mid W)}\left(1-\frac{P(R \mid L, W)}{P(R \mid H, W)}\right)=\frac{\theta(1-p)+(1-\theta) p}{\theta p+(1-\theta)(1-p)}-\frac{1-\theta}{\theta} .
$$

As $\theta>\frac{1}{2}>1-\theta$, this expression is strictly positive. Hence, if $\lambda$ is high enough, Condition (15) is automatically satisfied. We assume this is the case.

For the proposition to hold, it is necessary that $c_{v}$ is lower than the cost of inducing effort with a short-term contract under full transparency,

$$
\frac{d}{1-\frac{(1-\lambda) \theta}{\theta+\lambda(1-\theta)}-\lambda\left(\frac{1}{\theta+\lambda(1-\theta)}\right) \frac{(1-\theta)}{P(L \mid W)}} \leq p R-1<\frac{d}{1-\frac{P(H \mid S)}{P(H \mid W)}} .
$$

This will hold for some profit $R$ as long as

$$
\begin{aligned}
\frac{P(H \mid S)}{P(H \mid W)}>\frac{(1-\lambda) \theta}{\theta+\lambda(1-\theta)} & +\lambda\left(\frac{1}{\theta+\lambda(1-\theta)}\right) \frac{(1-\theta)}{P(L \mid W)} \Leftrightarrow \\
& \frac{1-\theta}{\theta p+(1-\theta)(1-p)}>\frac{(1-\lambda) \theta}{\theta+\lambda(1-\theta)} \\
& +\lambda\left(\frac{1}{\theta+\lambda(1-\theta)}\right) \frac{(1-\theta)}{(1-\theta) p+\theta(1-p)} .
\end{aligned}
$$

Note that the right-hand side is decreasing and continuous in $\lambda$ :

$$
\begin{aligned}
& \left.\frac{\partial\left(\frac{(1-\lambda) \theta}{\theta+\lambda(1-\theta)}+\lambda\left(\frac{1}{\theta+\lambda(1-\theta)}\right) \frac{(1-\theta)}{\partial \lambda}\right)}{(1-\theta) p+\theta(1-p)}\right) \\
& =\theta(2 \theta-1) \times \frac{p-1}{(\theta+\lambda-\theta \lambda)^{2}(p+\theta-2 p \theta)}<0 .
\end{aligned}
$$


Therefore, if the inequality holds strictly at $\lambda=1$, there is a $\underline{\lambda}<1$ such that if $\lambda \geq \underline{\lambda}$, it also holds strictly. Setting $\lambda=1$, the inequality becomes

$$
\frac{1-\theta}{\theta p+(1-\theta)(1-p)}>\frac{1-\theta}{(1-\theta) p+\theta(1-p)} .
$$

Since $\theta>\frac{1}{2}$, this holds if and only if $p<\frac{1}{2}$ and this completes the proof.

\section{C: Proof of Proposition 5}

We have to show that there exists a $\underline{\lambda}, R$, and a function $\phi^{*}(\lambda)$ with $m\left(\phi^{*}(\lambda)\right)>0$ such that, for all $\lambda \geq \underline{\lambda}$,

$$
c_{v}\left(\phi^{*}(\lambda)\right)<c_{s},
$$

and

$$
\frac{1-\lambda}{\lambda} \leq \frac{m\left(\phi^{*}(\lambda)\right) P(L \mid W)}{P(H \mid W)}\left(1-\frac{P(R \mid L, W)}{P(R \mid H, W)}\right) .
$$

If that is the case, there must be an $R$ such that

$$
c_{v}\left(\phi^{*}(\lambda)\right)<p R-1<c_{s},
$$

so that the project is feasible with manipulation and a vesting contract but not without. Recall

$$
c_{s} \equiv \frac{d}{1-\frac{P(H \mid S)}{P(H \mid W)}}=\frac{d}{1-\frac{1-\theta}{\theta p+(1-\theta)(1-p)}},
$$

and

$$
\begin{aligned}
c_{v}\left(\phi^{*}(\lambda)\right) & =\frac{d}{1-\frac{(1-\lambda) \theta}{\theta+\lambda m\left(\phi^{*}(\lambda)\right)(1-\theta)}-\lambda\left(\frac{(1-\theta)+m\left(\phi^{*}(\lambda)\right) \theta}{\theta+\lambda m\left(\phi^{*}(\lambda)\right)(1-\theta)}\right) \frac{(1-\theta)}{P(L \mid W)}} \\
& =\frac{d}{1-\frac{(1-\lambda) \theta}{\theta+\lambda m\left(\phi^{*}(\lambda)\right)(1-\theta)}-\lambda\left(\frac{(1-\theta)+m\left(\phi^{*}(\lambda)\right) \theta}{\theta+\lambda m\left(\phi^{*}(\lambda)\right)(1-\theta)}\right) \frac{(1-\theta)}{\theta(1-p)+(1-\theta) p}} .
\end{aligned}
$$

Set

$$
m\left(\phi^{*}(\lambda)\right)=\frac{1-\lambda}{\lambda \frac{P(L \mid W)}{P(H \mid W)}\left(1-\frac{P(R \mid L, W)}{P(R \mid H, W)}\right)}=\frac{1-\lambda}{\lambda\left(\frac{\theta(1-p)+(1-\theta) p}{\theta p+(1-\theta)(1-p)}-\frac{1-\theta}{\theta}\right)} .
$$

Note that $m\left(\phi^{*}(\lambda)\right)$ is continuous in $\lambda$ for $\lambda \in(0,1]$ and $c_{v}\left(\phi^{*}(\lambda)\right)$ is continuous in $m\left(\phi^{*}(\lambda)\right)$. Hence, $c_{v}\left(\phi^{*}(\lambda)\right)$ is continuous in $\lambda$ for $\lambda \in(0,1]$. Therefore, if we show that $c_{v}\left(\phi^{*}(\lambda)\right)<c_{s}$ for $\lambda=1$ (in which case $m\left(\phi^{*}(\lambda)\right)=0$ ), there must be some $\lambda<1$ such that this is still true for all $\lambda \in[\underline{\lambda}, 1) \geq \underline{\lambda}$ (in which case $m\left(\phi^{*}(\lambda)\right)>0$ ). Plugging in, we have

$$
c_{v}\left(\phi^{*}(1)\right)=\frac{d}{1-\left(\frac{1-\theta}{\theta}\right) \frac{1-\theta}{\theta(1-p)+(1-\theta) p}} .
$$

Thus, if

$$
\left(\frac{1-\theta}{\theta}\right) \frac{1-\theta}{\theta(1-p)+(1-\theta) p}<\frac{1-\theta}{\theta p+(1-\theta)(1-p)}
$$


the result follows. Simplifying the above inequality becomes

$$
(1-\theta)^{2}<\theta^{2},
$$

which is always true since $\theta>\frac{1}{2}$. When this holds, it is optimal to use a vesting contract, which we argue in the text and has the features described in the proposition.

\section{D: Comparative Statics}

\section{Proposition 6.}

1. If long-term contracts are optimal, the informativeness of earnings $1-m\left(\phi^{*}\right)$ is increasing in $\lambda$ and $\theta$ and decreasing in $p$.

2. The cost of the long-term contract is decreasing in $\theta$ and $\lambda$ and increasing in $p$, both for $m$ held fixed and when $m\left(\phi^{*}\right)$ is a function of $\theta, \lambda$, and $p$. The cost of the long-term contract is increasing in $m$.

3. The cost of the short-term contract is decreasing in $\theta$ and $p$ and increasing in $m$.

Proof. To show the first part of the proposition, note that we can write $m\left(\phi^{*}\right)$ as

$$
m\left(\phi^{*}\right) \equiv \max \left(\frac{\frac{1-\lambda}{\lambda}}{\frac{P(L \mid W)}{P(H \mid W)}\left(1-\frac{P(R \mid L, W)}{P(R \mid H, W)}\right)}, m(h)\right) .
$$

First, it is obvious that this is decreasing in $\lambda$. Next, define

$$
\begin{aligned}
g(\theta, p) & \equiv \frac{P(L \mid W)}{P(H \mid W)}\left(1-\frac{P(R \mid L, W)}{P(R \mid H, W)}\right) \\
& =\frac{p(1-\theta)+(1-p) \theta}{p \theta+(1-p)(1-\theta)}-\frac{1-\theta}{\theta} .
\end{aligned}
$$

Note that $m\left(\phi^{*}\right)$ is weakly decreasing in $g(\theta, p)$ and depends on $\theta$ and $p$ only through $g(\theta, p)$. Since $g(\theta, p)$ is increasing in $\theta$ and decreasing in $p$, the result in the proposition follows.

To show the next part of the proposition, define $\left.c_{v}(m) \equiv c_{v}(\phi)\right)$ where $m=m(\phi)$ and $f(\theta, p, \lambda, m)$ as

$$
\begin{aligned}
f(\theta, p, \lambda, m) \equiv \frac{d}{c_{v}(m)}= & 1-\frac{(1-\lambda) \theta}{\theta+\lambda m(1-\theta)} \\
& -\lambda\left(\frac{(1-\theta)+m \theta}{\theta+\lambda m(1-\theta)}\right) \frac{(1-\theta)}{p(1-\theta)+\theta(1-p)} .
\end{aligned}
$$

We have that

$$
\begin{aligned}
\frac{\partial f(\theta, p, \lambda, m)}{\partial m} & =-(2 \theta-1) \frac{\lambda}{(\theta+\lambda m(1-\theta))^{2}} \frac{(\lambda+p \theta(1-\lambda))(1-\theta)}{p(1-\theta)+\theta(1-p)} \\
& <0 .
\end{aligned}
$$

This follows since $2 \theta-1>0$. Hence, $c_{v}(m)$ is increasing in $m$. Since $m\left(\phi^{*}\right)$ is decreasing in $\lambda$ and $\theta$ and increasing in $p$, it is enough to show that the direct effect of these variables on $c_{v}(m)$ go in the same direction.

Defining $x=\frac{1-\theta}{\theta}$, we can rewrite $f$ as

$$
f(x, p, \lambda, m)=1-\frac{(1-\lambda)}{1+\lambda m x}-\lambda\left(\frac{x+m}{1+\lambda m x}\right) \frac{x}{p x+(1-p)} .
$$


Taking the derivative with respect to $x$, we have

$$
\begin{aligned}
\frac{\partial f(x, p, \lambda, m)}{\partial x}= & -\frac{\lambda}{(1+m x \lambda)^{2}(p x-p+1)^{2}} * \\
& {\left[( 1 - p ) \left(m \lambda\left(x^{2}+(1-p)\right)+2 x(1-m p)\right.\right.} \\
& +m p(1+2 x \lambda))+p x^{2}(1-m(\lambda m+(1-\lambda) p)] .
\end{aligned}
$$

Since $x$ is decreasing in $\theta, f$ is increasing $\theta$, so $c_{v}(m)$ is decreasing in $\theta$.

Next, we have

$$
\begin{aligned}
\frac{\partial f(\theta, p, \lambda, m)}{\partial p} & =-\lambda(1-\theta)(2 \theta-1) \frac{1-\theta+m \theta}{(\theta+m \lambda(1-\theta))(p+\theta-2 p \theta)^{2}} \\
& <0,
\end{aligned}
$$

so $c_{v}(m)$ is increasing in $p$. Also, we have

$$
\begin{aligned}
\frac{\partial f(\theta, p, \lambda, m)}{\partial \lambda} & =\theta \frac{2 \theta-1}{(\theta+m \lambda-m \theta \lambda)^{2}(p+\theta-2 p \theta)}(1-p(\theta+m(1-\theta))) \\
& >0
\end{aligned}
$$

so $c_{v}(m)$ is decreasing in $\lambda$.

Finally, we show that $c_{s}(h)$ is decreasing in $\theta$ and $p$ and increasing in $m$. Define $n(\theta, p, m)$ as

$$
\begin{aligned}
n(\theta, p, m) & \equiv \frac{P(H \mid S)+m P(L \mid S)}{P(H \mid W)+m P(L \mid W)} \\
& =\frac{1-\theta+m \theta}{p \theta+(1-p)(1-\theta)+m((1-p) \theta+p(1-\theta))} .
\end{aligned}
$$

Since $c_{s}(h)$ depends on $\theta, p$, and $m$ only through $n(\theta, p, m)$ and is increasing in $n(\theta, p, m)$, it is enough to show that the comparative statics hold for $n(\theta, p, m)$. We have that

$$
\begin{aligned}
& \frac{\partial n(\theta, p, m)}{\partial \theta}=p \frac{m^{2}-1}{(p \theta+(1-p)(1-\theta)+m((1-p) \theta+p(1-\theta)))^{2}} \\
&<0 . \\
& \frac{\partial n(\theta, p, m)}{\partial m}=p \frac{2 \theta-1}{(p \theta+(1-p)(1-\theta)+m((1-p) \theta+p(1-\theta)))^{2}} \\
&>0 . \\
& \frac{\partial n(\theta, p, m)}{\partial p}=-(2 \theta-1)(1-m) \\
& \times \frac{1-\theta+m \theta}{(p \theta+(1-p)(1-\theta)+m((1-p) \theta+p(1-\theta)))^{2}}<0 .
\end{aligned}
$$

\section{References}

Acharya, V. V., K. John, and R. K. Sundaram. 2000. On the Optimality of Resetting Executive Stock Options. Journal of Financial Economics 57:65-101. 
Aghion, P., P. Bolton, and J. Tirole. 2004. Exit Options in Corporate Finance: Liquidity versus Incentives. Review of Finance 8:1-27.

Akerlof, G. A. 1970. The Market for Lemons: Quality Uncertainty and the Market Mechanism. Quarterly Journal of Economics 84:488-500.

Bartov, E., and P. Mohanram. 2004. Private Information, Earnings Manipulations, and Executive Stock Option Exercises. The Accounting Review 79:889-920.

Bebchuk, L., and J. Fried. 2004. Pay Without Performance: The Unfulfilled Promise of Executive Compensation. Cambridge: Harvard University Press.

Bolton, P., J. Scheinkman, and W. Xiong. 2006. Executive Compensation and Short-Termist Behavior in Speculative Markets. Review of Economic Studies 73:577-610.

Burns, N., and S. Kedia. 2006. The Impact of Performance-Based Compensation on Misreporting. Journal of Financial Economics 79:35-67.

Burns, N., and S. Kedia. 2008. Executive Option Exercise and Financial Misreporting. Journal of Banking and Finance 32:845-57.

Cremer, J. 1995. Arm's Length Relationships. Quarterly Journal of Economics 110:275-95.

Dewatripont, M. 1989. Renegotiation and Information Revelation over Time: The Case of Optimal Labor Contracts. Quarterly Journal of Economics 104:589-619.

Dewatripont, M., and E. Maskin. 1995. Contractual Contingencies and Renegotiation. RAND Journal of Economics 26:704-19.

Fudenberg, D., and J. Tirole. 1990. Moral Hazard and Renegotiation in Agency Contracts. Econometrica 58:1279319.

Gaver, J. J., K. M. Gaver, and J. R. Austin. 1995. Additional Evidence on Bonus Plans and Income Management. Journal of Accounting and Economics 19:3-28.

Hart, O. D., and J. Tirole. 1988. Contract Renegotiation and Coasian Dynamics. Review of Economic Studies 55:509-40.

Healy, P. M. 1985. The Effect of Bonus Schemes on Accounting Decisions. Journal of Accounting and Economics $7: 85-107$.

Healy, P. M., and K. G. Palepu. 2003. The Fall of Enron. Journal of Economic Perspectives 17:3-26.

Holmström, B., and S. N. Kaplan. 2003. The State of U.S. Corporate Governance: What's Right and What's Wrong. Journal of Applied Corporate Finance 15:8-20.

Holthausen, R. W., D. F. Larcker, and R. G. Sloan. 1995. Annual Bonus Schemes and the Manipulation of Earnings. Journal of Accounting and Economics 19:29-74.

Jensen, M. C., and K. J. Murphy. 2004. Remuneration: Where We've Been, How We Got to Here, What Are the Problems, and How to Fix Them. Working Paper 44/2004, European Corporate Governance Institute.

Kole, S. R. 1997. The Complexity of Compensation Contracts. Journal of Financial Economics 43:79-104.

Lazear, E. P. 2004. Output-Based Pay: Incentives or Sorting?, in Solomon W. Polachek (ed.), Accounting for Worker Well-Being, Research in Labor Economics, 23, pp. 1-25, JAI/Elsevier, Amsterdam, San Diego and Oxford.

Maskin, E., and J. Tirole. 1992. The Principal-Agent Relationship with an Informed Principal II: Common Values. Econometrica 60:1-42.

Murphy, K. J. 1999. Executive Compensation, in O. Ashenfelter and D. Card (eds.), Handbook of Labor Economics, Amsterdam: Elsevier Science/North Holland.

Myers, S., and R. G. Rajan. 1998. The Paradox of Liquidity. Quarterly Journal of Economics 113:733-71. 
Oyer, P. 2004. Why Do Firms Use Incentives That Have No Incentive Effects? Journal of Finance 59:1619-49.

Rajan, R. G. 1992. Insiders and Outsiders: The Choice Between Informed and Arm's Length Debt. Journal of Finance 47:1367-400.

Stein, J. C. 1989. Efficient Capital Markets, Inefficient Firms: A Model of Myopic Corporate Behavior. Journal of Finance 104:655-69. 